\title{
Influência da Adição e da Modificação Química de uma Carga Mineral Nanoparticulada nas Propriedades Mecânicas e no Envelhecimento Térmico de Compósitos Poliuretano/sisal
}

\author{
Maria Roberta 0. Pinto \\ Departamento de Química, UEPB \\ Mauri M. A. Júnior \\ Engenharia de Materiais, UFCG

\section{Suédina M. I. Silva, Laura H. Carvalho Departamento de Engenharia de Materiais, UFCG}

\begin{abstract}
Resumo: Este trabalho trata do efeito da hibridização do reforço, através da adição de uma carga mineral (bentonita) nanoparticulada, no desempenho mecânico de compósitos poliuretano/sisal contendo $25 \%$ em massa de fibras de sisal e moldados por compressão. As propriedades mecânicas, de tração e impacto, dos sistemas compósitos estudados foram avaliadas em função do teor (0-10\% em massa) e de modificações químicas da carga mineral. Os efeitos do envelhecimento térmico nas propriedades tênseis $(\sigma, \mathrm{E}, \varepsilon)$ de compósitos selecionados também foram investigados. $\mathrm{O}$ reforço mineral (Bentonita sódica Brasgel-PA) foi empregado em quatro formas, a saber: a) como fornecido (sem tratamento), b) tratado com ácido clorídrico $(0,6 \mathrm{~N})$, c) modificado com cloreto de dodecil dimetil benzil amônio (Dodigen) e d) modificado com brometo de cetil trimetil amônio (Cetremide). Os resultados indicam que a incorporação da bentonita eleva as propriedades mecânicas dos compósitos e que melhores propriedades foram obtidas quando a bentonita foi tratada com o ácido clorídrico. O envelhecimento térmico em tempos curtos (até 4 dias) provocou elevação no módulo elástico e resistência na ruptura dos compósitos, o que foi atribuído à pós-cura da matriz. Em tempos longos (32 dias) a exposição térmica causou decréscimo nas propriedades tênseis $(\sigma, \mathrm{E}, \varepsilon)$ dos compósitos investigados, o que foi atribuído à degradação oxidativa da matriz e dos reforços. O compósito mais resistente ao envelhecimento térmico foi o híbrido cuja carga mineral foi organofilizada com o sal Cetremide. Anáslies por DRX e MEV indicam que a estrutura dos compósitos híbridos é um misto de micro e nanocompósito.
\end{abstract}

Palavras-chave: Poliuretano, cargas nanoparticuladas, propriedades mecânicas, envelhecimento térmico.

\section{Influence of a Nanoparticulate Mineral Filler Addition and Chemical Modification of The Mechanical Properties and Thermal Aging of PU/Sisal Composites}

Abstract: This work deals with filler hybridization effects, by the addition of a nanoparticulate mineral filler (bentonite), on the mechanical performance of compression molded Polyurethane/sisal composites with $25 \mathrm{wt} \%$ fiber content. Composite tensile and impact properties were evaluated as a function of mineral filler content $(0-10 \mathrm{wt} \%)$ and chemical modifications. Thermal aging effects onf tensile $(\sigma, \mathrm{E}, \varepsilon)$ properties of selected composites were also ascertained. The mineral filler (Brasgel PA sodium bentonite) was employed in the following forms: a) as received; b) treated with a $0,6 \mathrm{~N}$ $\mathrm{HCl}$ solution; c) chemically modified with dodecyl dimethyl benzyl ammonium chloride (Dodigen) and d) chemically modified with cetyl trimethyl ammonium bromide (Cetremide). Our results show that bentonite addition increases the mechanical properties of PU/sisal composites and that best overall mechanical performances was achieved with addition of the hydrochloric acid trated mineral filler. Thermal aging for short times (up to 4 days) led to small increases in composite's elastic modulus na tensile strengths, which was attributed to post-curing of the matrix. Long thermal exposure (32 days) led to decreases in composite tensile properties $(\sigma, \mathrm{E}, \varepsilon)$, which was attributed to oxidative degradation of both: matrix and sisal fibers. The most thermally resistant composite was the hybrid (PU/sisal-bentonite) whose mineral filler was chemically modified with Cetremide. DRX and SEM data indicate the hybrids with organofilized bentonites to be composed of micro and nanocomposite structures.

Keywords: Poliurethane, nanoparticulate fillers, mechanical properties, thermal aging.

Autor para correspondência: Laura H. Carvalho, Departamento de Engenharia de Materiais, UFCG, Av. Aprígio Veloso 882 -Bodocongó, C.P. 10034, CEP: 58109-970, Campina Grande, PB. E-mail: laura@dema.ufcg.edu.br 


\section{Introdução}

A utilização de fibras naturais como reforço em compósitos poliméricos tem recebido atenção considerável nos últimos anos, uma vez que as fibras naturais são fortes, leves, abundantes, não abrasivas, têm baixo custo, são biodegradáveis e possuem dureza e resistência específica moderada ${ }^{[1,2]}$.

Quando fibras vegetais são associadas à resinas derivadas de óleos vegetais forma-se uma classe de materiais chamada de "eco-composite" ${ }^{[3]}$. As matérias-primas de origem vegetal além de serem oriundas de fontes renováveis atendem aos requisitos de biodegradabilidade e de não contaminação do meio ambiente.

Investigações preliminares mostram que a fibra de sisal pode ser usada como reforço em matrizes poliméricas apresentando elevada resistência ao impacto e propriedades em tração e em flexão moderadas ${ }^{[4]}$.

Nanocompósitos poliméricos compreendem uma nova classe de materiais onde substâncias inorgânicas de dimensões nanométricas, tais como argilas e outros minerais, são finamente dispersos dentro de uma matriz polimérica ${ }^{[5]}$. Um dos sistemas mais promissores é um híbrido baseado em polímeros orgânicos e argilominerais inorgânicos, constituídos de silicatos em camadas ${ }^{[6]}$. Os nanocompósitos poliméricos exibem boas propriedades óticas além de apresentarem propriedades superiores às dos polímeros puros ou às dos compósitos convencionais. Aumentos significativos são observados para as propriedades de barreira a gases, módulo de elasticidade, resistência à tração, resistência a solventes e ao fogo entre outras ${ }^{[7]}$. Vale salientar que, em nanocompósitos, esses aumentos são encontrados em baixos teores do componente inorgânico (1-10\% em massa) enquanto, em polímeros carregados convencionalmente, teores de carga mineral de 25 a $40 \%$, em massa ${ }^{[5]}$, via de regra, são necessários para que propriedades superiores à da matriz sejam obtidas. A argila mais empregada na área de nanocompósitos baseados em polímero-silicatos em camadas é a bentonita, cujo argilomineral predominante é a montmorilonita. Esta argila é abundante no estado da Paraíba e pertence ao grupo das esmectitas ${ }^{[8]}$.

O presente trabalho trata da influência da adição de uma carga nanoparticulada (bentonita) nas propriedades mecânicas e no envelhecimento térmico de compósitos poliuretano/ sisal contendo $25 \%$ em massa de fibras. Como matriz empregou-se uma poliuretana reticulada derivada do óleo de mamona e, como reforços, fibras curtas de sisal e bentonita sódica industrializada (Brasgel PA) e modificada quimicamente. Os compósitos foram moldados por compressão e suas propriedades determinadas em função do teor $(0-10 \% \mathrm{em}$ massa) e tratamento da carga mineral nanoparticulada adicionada. As cargas minerais foram adicionadas nas formas: a) sódica, tal como recebida (Brasgel PA); b) esfoliada com $\mathrm{HCl}$; e, c) quimicamente modificada (organofilizada) com cloreto de dodecil dimetil benzil amônio e d) quimicamente modificada (organofilizada) com brometo de cetil trimetil amônioCetremide.

\section{Experimental}

\section{Materiais}

A matriz poliuretana foi obtida pela mistura de um poliol (Garicin A230) com índice de hidroxilas de $230 \mathrm{mgKOH} / \mathrm{g}$, e de um pré-polímero de isocianato modificado (M25) com $15 \%$ de isocianato livre, numa proporção de $1 / 0,7(\mathrm{~m} / \mathrm{m})$ conforme instruções do fabricante. Ambos os insumos são derivados do óleo de mamona e cedidos pela Proquinor S.A. As fibras de sisal utilizadas neste estudo eram provenientes da região de Pocinhos - PB e a carga mineral nanoparticulada foi uma bentonita sódica industrializada (Brasgel-PA) cedida pela Bentonit União Nordeste (BUN).

As fibras de sisal foram lavadas em água corrente para remover as impurezas - solo, poeira, resíduos de desfibramento - e secas à temperatura ambiente por $48 \mathrm{~h}$. Posteriormente, as fibras foram agrupadas em feixes, penteadas e cortadas em comprimentos de 10 a $15 \mathrm{~mm}$. As amostras de bentonita foram passadas em peneira $A B N T n^{\circ} 200$ e sujeitas a três tratamentos distintos: a) com uma solução de ácido clorídrico $0,6 \mathrm{~N}, \mathrm{~b}$ ) com o cloreto de dodecil dimetil benzil amônio (Dodigen) e c) com brometo de cetil trimetil amônio (Cetremide).

\section{Metodologia}

\section{Tratamento da Argila}

No tratamento com ácido clorídrico a $0,6 \mathrm{~N}$ foram preparadas dispersões de $300 \mathrm{meq} / 100 \mathrm{~g}$ de argila. Esta dispersão foi aquecida à ebulição, sob refluxo e com agitação constante por 2 horas, filtrada, lavada com água destilada quente $\left(80^{\circ} \mathrm{C}\right)$ até a neutralidade, seca em estufa à $80^{\circ} \mathrm{C}$ por $48 \mathrm{~h}$, triturada em almofariz e passada em peneira ABNT $n^{\circ} 200$ (abertura $=0,074 \mathrm{~mm}$ ).

O tratamento com o sal Dodigen é uma variante do procedimento reportado por Valenzuela Díaz ${ }^{[9]}$. Foram preparadas dispersões de $4 \%$, em massa, de argila em água destilada. A argila foi adicionada lentamente à água, e a dispersão mantida sob agitação mecânica (3000 rpm). Decorridos 20 minutos, adicionou-se à dispersão, $20 \mathrm{ml}$ de uma solução $(1,02 \mathrm{~g} / \mathrm{L})$ do sal quaternário de amônio em água destilada, sob agitação mecânica, mantida por mais 20 minutos. A dispersão aquosa contendo $0,03 \mathrm{~g} / \mathrm{L}$ de sal foi deixada em repouso por 24 horas, antes de ser filtrada e lavada com $2000 \mathrm{~mL}$ de água destilada (em alíquotas de $200 \mathrm{ml}$ ) na temperatura ambiente, até a eliminação de cloretos, verificada através da adição de nitrato de prata $0,025 \mathrm{M}$ ao líquido de lavagem. A argila quimicamente modificada foi seca em estufa a $60^{\circ} \mathrm{C}$ por $48 \mathrm{~h}$ antes de ser triturada em almofariz e passada em peneira ABNT $n^{\circ}$ 200 (abertura $=0,074 \mathrm{~mm}$ ).

Procedimento levemente distinto, que também tomou por base procedimento reportado por Valenzuela Díaz ${ }^{[9]}$, foi utilizado para o tratamento da bentonita com o sal Cetremide. Neste caso, foram preparadas dispersões $2 \%$ de argila em água destilada quente $\left(80 \pm 5^{\circ} \mathrm{C}\right)$. A argila foi adicionada aos poucos e 
mantida sob agitação mecânica (3000 rpm) por 20 minutos, quando então o sal Cetremide $(0,006 \mathrm{~g} / \mathrm{L})$ foi adicionado à dispersão e a agitação mantida por mais 30 minutos e a agitação foi cessada. A mistura foi mantida em repouso por 24 horas na temperatura ambiente e a argila assim tratada foi seca em estufa a $60{ }^{\circ} \mathrm{C}$ por $48 \mathrm{~h}$, triturada em almofariz e passada em peneira $A B N T n^{\circ} 200$ (abertura $=0,074 \mathrm{~mm}$ ).

\section{Preparação dos Híbridos PU/Sisal-Bentonita}

As bentonitas (natural e tratadas) foram secas em estufa $\left(110 \pm 5^{\circ} \mathrm{C}\right)$ por 1 hora, antes de serem misturadas ao poliol. As dispersões, com teores de até $10 \%$ em massa de bentonita em poliol, foram mantidas sob agitação mecânica $(600 \mathrm{rpm})$ na temperatura ambiente por 1 hora. Devido à natureza higroscópica dos insumos e visando diminuir a formação de bolhas durante a moldagem, as fibras, a dispersão e o prépolímero isocianato foram colocados em estufa de circulação forçada de ar operando a $80^{\circ} \mathrm{C}$ por 30 minutos, imediatamente antes que o pré-polímero isocianato fosse misturado (agitação manual por 1 minuto) com o sistema argila-poliol. Esta mistura então foi vertida no molde (200x180x3mm) contendo as fibras de sisal ( $25 \% \mathrm{em}$ massa) previamente secas e dispostas de forma aleatória no interior do molde. O molde foi fechado e uma carga de 8 toneladas foi aplicada e mantida por 4 horas à temperatura ambiente e somente então as placas foram desmoldadas.

\section{Caracterização Mecânica}

Os ensaios mecânicos em tração foram conduzidos segundo as normas ASTM D-3039 em máquina universal de ensaios Lloyd LR-10K, operando na temperatura ambiente e a uma taxa de deslocamento da travessa de $5 \mathrm{~mm} / \mathrm{min}$. Corpos de prova retangulares, nas dimensões preconizadas pela norma ASTM D3039 (110 x 12,7 x $3 \mathrm{~mm})$, foram serrados manualmente a partir das placas obtidas por compressão, e o acabamento dado por lixas de $\mathrm{n}^{\circ} 100$ e 180 .

Os ensaios de resistência ao impacto IZOD foram realizados segundo a norma ASTM D-256, na temperatura ambiente, em equipamento de ensaios de impacto Ceast Resil 5,5 J operando com um martelo de 5,5 J, em amostras não entalhadas. As dimensões das amostras para o ensaio de impacto foram de $65 \times 12,7 \times 3 \mathrm{~mm}$.

Os resultados reportados para os ensaios mecânicos são valores médios utilizando um mínimo de 6 corpos-de-prova por composição.

\section{Caracterização Morfológica}

A análise morfológica das superfícies de fratura das amostras testadas em tração, recobertas com carbono, foi realizada por microscopia eletrônica de varredura (MEV) em microscópio eletrônico Shimadzu, modelo SSX-550 com detector de retro-espalhamento, sistema de baixo vácuo e micro-análise por EDX.

\section{Envelhecimento Térmico}

O envelhecimento térmico foi conduzido em uma estufa de circulação forçada de ar operando a uma temperatura de $110 \pm 5^{\circ} \mathrm{C}$, segundo a norma ASTM D3045-74, em corposde-prova expostos termicamente por tempos de até 32 dias. As amostras foram removidas em tempos pré-estabelecidos e, após resfriamento até a temperatura ambiente, suas propriedades mecânicas em tração $(\sigma, \mathrm{E}, \varepsilon)$ foram determinadas.

\section{Resultados e Discussão}

\section{Caracterização Mecânica}

$\mathrm{O}$ efeito da incorporação da bentonita natural (sem tratamento) nas propriedades mecânicas de compósitos PU/sisal foi avaliado e os dados obtidos estão reportados na Tabela 1.

Os resultados indicam um aumento na resistência à tração do compósito poliuretano/sisal quando teores de até 7\% em massa de bentonita foram adicionados. Os componentes individuais (fibra celulósica e carga mineral) apresentam grupos hidroxila que podem reagir com os grupos isocianato livres do poliuretano promovendo maiores interações fibrabentonita-matriz ${ }^{[10]}$. Um aumento subseqüente no teor de carga mineral, de 7 para (10\%), causou uma redução na resistência à tração e módulo elástico dos sistemas o que, acredita-se, pode ser atribuído à formação de aglomerados e/ou à má dispersão da carga mineral em teores mais elevados. Comportamento análogo foi observado em estudo anterior realizado em sistema afim ${ }^{[11]}$.

Comportamento análogo foi observado para o módulo de elasticidade dos híbridos que aumentou com a introdução da carga nanoparticulada e, diminuiu quando teores mais elevados ( $10 \%$ em massa) de carga mineral foram adicionados. Valores otimizados foram obtidos para teores de bentonita entre 5 e $7 \%$ em massa. $\mathrm{O}$ aumento no módulo, com a adição da carga nanoparticulada, foi atribuído ao aumento no teor total de reforço e/ou a uma possível sinergia entre os mecanismos de atuação dos reforços já que a carga fibrosa atua por transferência de tensões enquanto, a carga nanoparticulada, provoca enrijecimento por dispersã ${ }^{[11]}$.

$\mathrm{O}$ alongamento na ruptura dos híbridos não foi alterado com a incorporação de até $5 \%$ em massa de bentonita. Entretanto, a incorporação de teores mais elevados (7 e 10\% em massa) resultou em acentuada redução desta propriedade. Isto já era esperado e tido como conseqüência do aumento no teor total de cargas provocando o enrijecimento dos compósitos ${ }^{[11]}$.

Tabela 1. Efeito da adição de bentonita nas propriedades mecânicas de compósitos Poliuretano/sisal, contendo $25 \%$ em massa de fibras.

\begin{tabular}{ccccc}
\hline $\begin{array}{c}\text { Bentonita } \\
(\%)\end{array}$ & $\begin{array}{c}\boldsymbol{\sigma}_{\mathbf{y}} \\
(\mathbf{M p a})\end{array}$ & $\begin{array}{c}\mathbf{E} \\
(\mathbf{M p a})\end{array}$ & $\begin{array}{c}\boldsymbol{\varepsilon r} \\
(\boldsymbol{\%})\end{array}$ & $\begin{array}{c}\text { R.IIzod } \\
(\mathbf{J} / \mathbf{m})\end{array}$ \\
\hline 0 & $19 \pm 3$ & $914 \pm 141$ & $5,7 \pm 0,1$ & $448 \pm 42$ \\
2 & $24 \pm 3$ & $1227 \pm 65$ & $5,5 \pm 0,8$ & $502 \pm 10$ \\
5 & $24 \pm 3$ & $1263 \pm 87$ & $5,5 \pm 0,9$ & $598 \pm 41$ \\
7 & $22 \pm 3$ & $1387 \pm 127$ & $3,2 \pm 0,5$ & $512 \pm 61$ \\
10 & $13 \pm 1$ & $1058 \pm 71$ & $3,0 \pm 0,7$ & $532 \pm 5$ \\
\hline
\end{tabular}


O aumento da resistência ao impacto dos híbridos com o teor de carga nanoparticulada foi associado ao aumento na resistência à tração sem redução significativa no alongamento na ruptura até $5 \%$ em massa de bentonita. É provável que a introdução da carga nanoparticulada ao compósito poliuretana/juta tenha sido capaz de inserir um mecanismo adicional de dissipação de energia, provocando um aumento na resistência ao impacto ${ }^{[12,13]}$. O valor otimizado para esta propriedade foi alcançado com a adição de $5 \%$ em massa de bentonita. Em teores mais elevados a resistência ao impacto dos híbridos tendeu a diminuir, o que foi atribuído à elevação do teor total de carga e à formação de maior número e/ou tamanho de aglomerados capazes de concentrar tensões ${ }^{[13]}$. Mesmo assim, valores levemente superiores ao do compósito poliuretana/sisal foram obtidos, indicando que a incorporação da carga mineral em teores de até $10 \%$ em massa aos compósitos poliuretana/sisal com $25 \%$ em massa de fibras de sisal, ainda é capaz de tenacificar o produto.

Considerando que, de uma forma geral, as melhores propriedades mecânicas dos híbridos PU/sisal-bentonita foram obtidos com a adição de $5 \%$ em peso de bentonita, este foi o teor escolhido para se investigar o efeito de modificações químicas da carga mineral nas propriedades mecânicas dos compósitos com reforços híbridos vegetal-mineral. A escolha do uso de um teor fixo de fibra vegetal ( $25 \%$ em massa) é resultado de estudo anterior onde, os compósitos com este teor específico de fibras, foram os que apresentaram propriedades mecânicas superiores e de maior reprodutibilidade para o sistema poliuretana/sisa ${ }^{[14]}$.

Os resultados obtidos para os efeitos dos tratamentos químicos adotados na resistência à tração, módulo de elasticidade, alongamento na ruptura e resistência ao impacto dos híbridos PU/sisal-bentonita contendo $25 \%$ em massa de sisal e $5 \%$ em massa de bentonita tratada estão mostrados na Tabela 2 .

Os resultados indicam que, dentre as modificações químicas utilizadas, o tratamento com o ácido clorídrico foi o mais eficaz. Estudos anteriores demonstraram que, sob as condições de tratamento ácido utilizado, houve uma esfoliação da argila e um aumento significativo em sua área superficial $^{[15]}$. Portanto, atribui-se os aumentos verificados para a resistência à tração, módulo de elasticidade e resistência ao impacto, a este aumento na área superficial da carga. $\mathrm{O}$ efei-

Tabela 2. Efeito do tratamento da bentonita nas propriedades mecânicas dos compósitos de poliuretano/sisal, contendo $25 \%$ em massa de fibras e $5 \%$ em massa de bentonita.

\begin{tabular}{ccccc}
\hline Tratamento & $\begin{array}{c}\boldsymbol{\sigma y} \\
(\mathbf{M p a})\end{array}$ & $\begin{array}{c}\mathbf{E} \\
(\mathbf{M p a})\end{array}$ & $\begin{array}{c}\boldsymbol{\varepsilon}_{\mathbf{r}} \\
(\boldsymbol{\%})\end{array}$ & $\begin{array}{c}\text { R.IIzod } \\
(\mathbf{J} / \mathbf{m})\end{array}$ \\
\hline Nenhum & $24 \pm 3$ & $1263 \pm 87$ & $5,5 \pm 0,9$ & $598 \pm 41$ \\
$\mathrm{HCl}$ & $29 \pm 1$ & $1430 \pm 79$ & $4,1 \pm 0,4$ & $1051 \pm 59$ \\
Dodigen & $19 \pm 0,5$ & $1356 \pm 21$ & $4,4 \pm 0,8$ & $670 \pm 80$ \\
Cetremide & $21 \pm 0,5$ & $1102 \pm 33$ & $4,5 \pm 0,7$ & $711 \pm 45$ \\
\hline
\end{tabular}
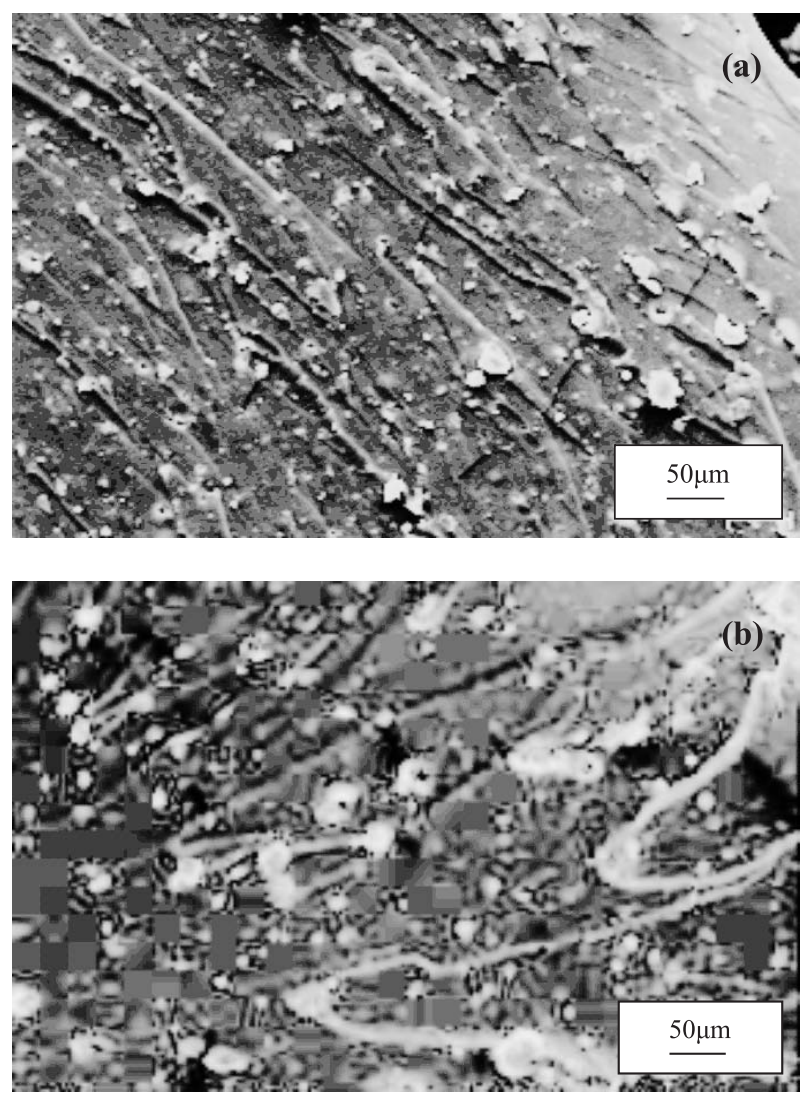

Figura 1. Fotomicrografia obtida por microscopia eletrônica de varredura: (a) do compósito Poliuretano/bentonita tratada com $\mathrm{HCl}$ e (b) do compósito Poliuretano/bentonita natural, ambos contendo 5\% em massa de bentonita.

to do tratamento superficial da bentonita com ácido clorídrico é apresentado nas Figuras 1a e $1 b$.

As micrografias dos compósitos Poliuretana/bentonita com $5 \%$ de carga corroboram os dados reportados em estudo anterior $^{[14-15]}$ que mostram que o tratamento da bentonita com $\mathrm{HCl}$ leva a compósitos com aglomerados de carga mineral com tamanhos inferiores aos obtidos para os compósitos com argila sem tratamento.

Os tratamentos com os sais quaternários de amônio (Dodigen e Cetremide) não foram tão eficazes quanto o tratamento ácido no que se refere ao aumento provocado nas propriedades mecânicas dos compósitos híbridos. Mesmo assim, o módulo de elasticidade e a resistência ao impacto daqueles compósitos foram ligeiramente superiores aos do compósito híbrido sisal-bentonita reforçado com a carga mineral não tratada (Tabela 2).

Esperava-se que a incorporação das argilas organofilizadas com os dois sais quaternários, levasse à formação de um sistema micro e nanocompósito. Análises de difração de raios-X (Figura 2a) indicam que, em ambos os casos, a organofilização foi eficaz, levando à intercalação das camadas de argila, conforme observado pelo aumento da distância interplanar basal $\left(\mathrm{d}_{001}=13,00 \AA\right.$ para a argila Brasgel PA; $\mathrm{d}_{001}=16,07 \AA$ para a tratada com $\mathrm{HCl} ; \mathrm{d}_{001}=17,67 \AA$ para a tratada com o sal Dodigen e $\mathrm{d}_{001}=29,45 \AA$ para a argila tratada com o sal Cetremide). 

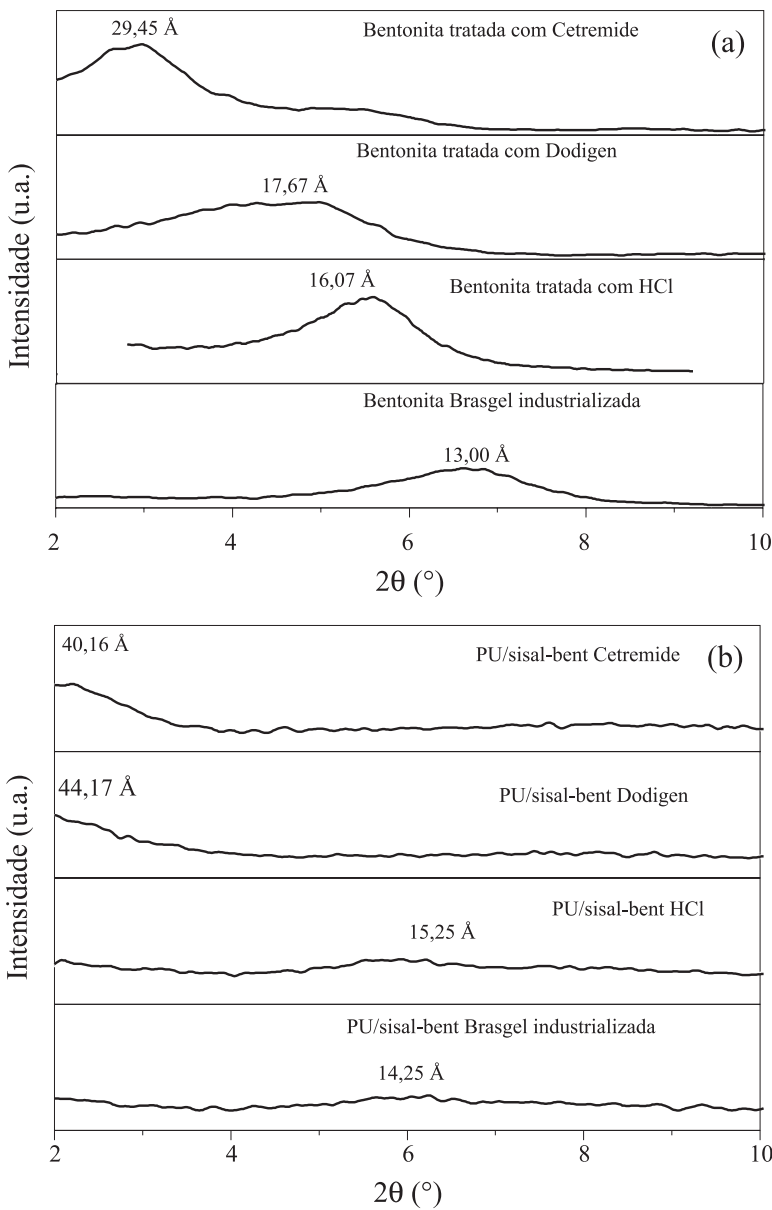

Figura 2. Difratogramas de raio-X ilustrando o efeito das modificações químicas em: (a) bentonitas; (b) bentonitas nos compósitos híbridos poliuretano/sisal-bentonita.

Os difratogramas dos compósitos híbridos poliuretano/ sisal-bentonita sódica Brasgel-PA e quimicamente modificadas estão apresentados na Figura 2b Fica evidenciado que, no híbrido, a carga mineral não modificada e a tratada com ácido clorídrico apresentaram valores para o pico correspondente à distância interplanar basal, $\mathrm{d}_{001}$, de 14,25 e de $15,25 \AA$, respectivamente, ou seja, muito semelhantes ao apresentado pela bentonita sódica Brasgel PA $\left(\mathrm{d}_{001}=13,00 \AA\right)$, o que indica que não houve a formação de nanocompósito. Por outro lado, a adição da bentonita tratada com os sais Dodigen e Cetremide ao compósito poliuretano/sisal resultou na formação de nanocompósitos. Isto porque, como mostrado na Figura $2 \mathrm{~b}$ houve aumento significativo nas distâncias interplanares basais das bentonitas tratadas com os sais Dodigen e Cetremide, quando estas foram incorporadas ao compósito. Neste caso, os valores para estas distâncias passaram de $17,67 \AA$ e $29,45 \AA$, a $44,17 \AA$ e $40,16 \AA$, respectivamente quando as bentonitas organofilizadas com os sais quaternários de amônio Dodigen e Cetremide foram incorporadas ao compósito poliuretana/sisal.

Apesar disto, a microscopia eletrônica de varredura ( $\mathrm{Fi}$ guras 3 a-b) mostra a formação de aglomerados de partículas nos compósitos híbridos contendo as cargas minerais organofilizadas, o que sinaliza a formação de uma estrutura
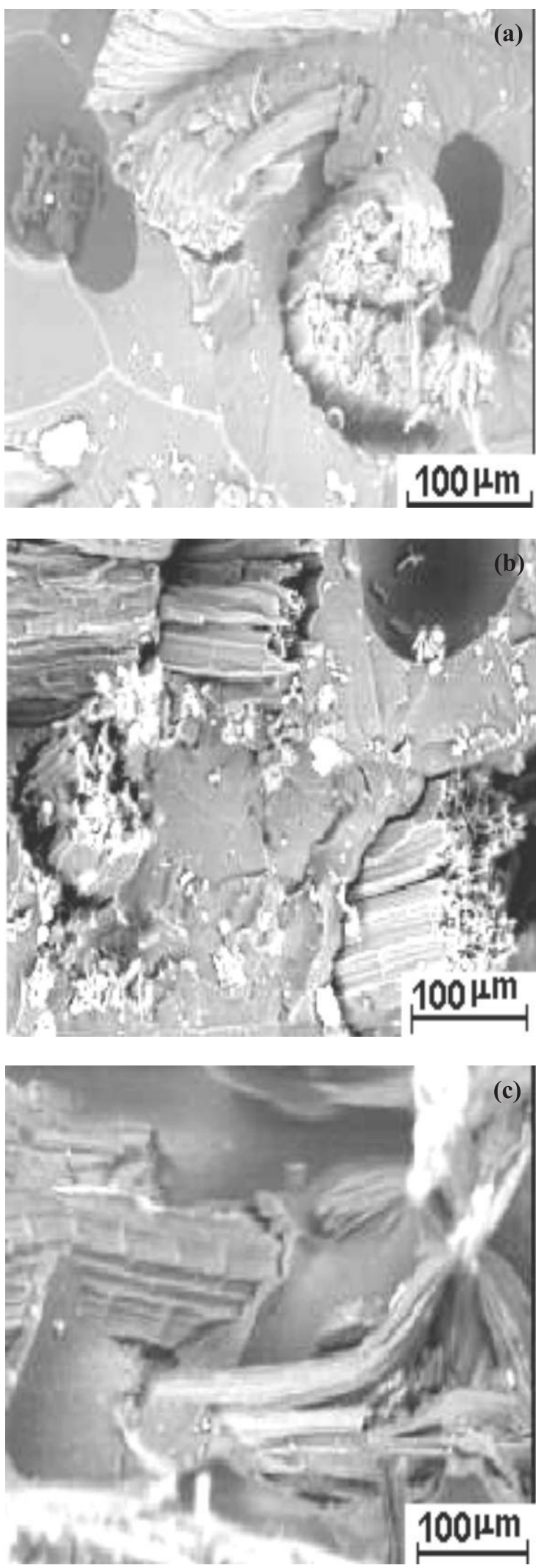

Figura 3. Fotomicrografias (MEV) de compósitos PU/sisal-bentonita com carga mineral não modificada (a) organofilizada com sal; (b) Dodigen; (c) Cetremide.

composta de nanocompósito intercalado (Raio-X) e de microcompósito (MEV). 


\section{Envelhecimento Térmico}

Os efeitos do envelhecimento térmico na resistência à tração, módulo de elasticidade e alongamento na ruptura dos híbridos poliuretano/sisal-bentonita estão apresentado na Figuras 4(a-c).

Os dados indicam que, em tempos longos (32 dias) de exposição térmica, houve um decréscimo nas propriedades mecânicas em tração, principalmente na resistência à tração e no módulo elástico, para todos os sistemas compostos in-
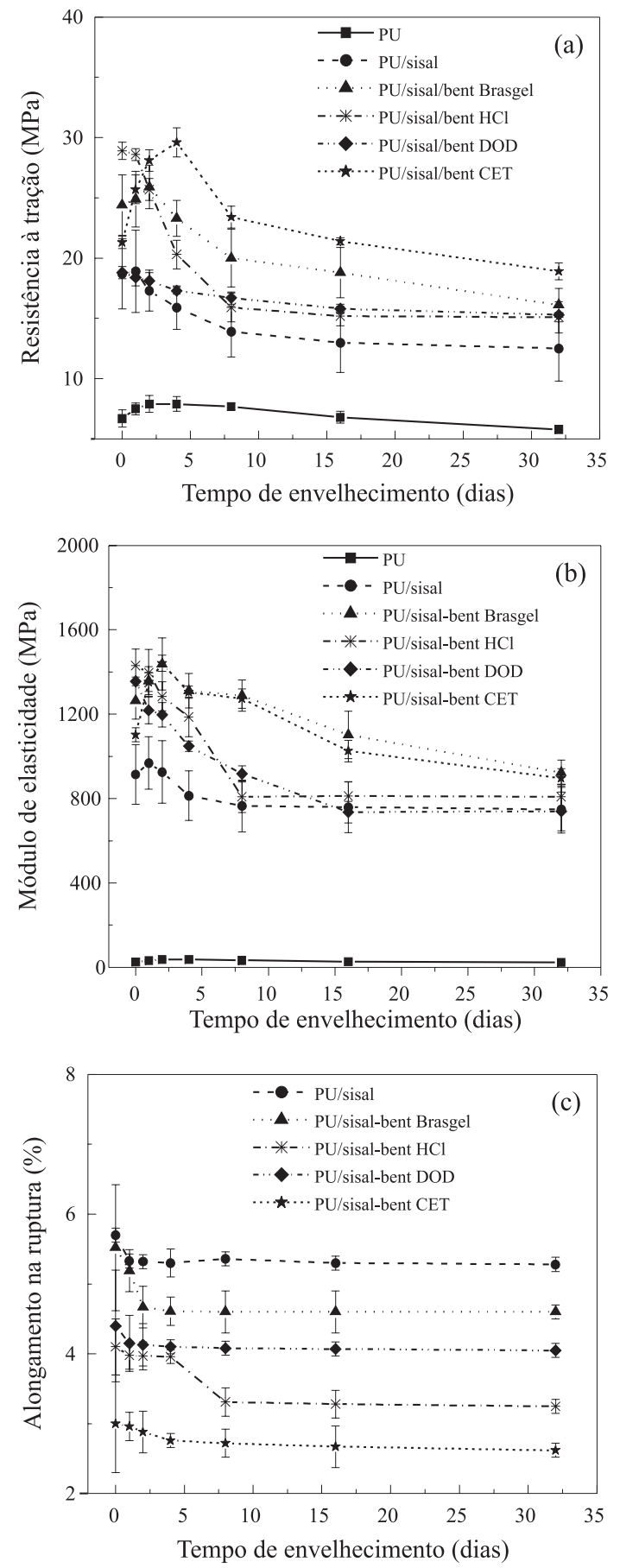

Figura 4. Efeito do tempo de envelhecimento térmico e da modificação química da bentonita nas propriedades mecânicas em tração $(\sigma, \mathrm{E}, \varepsilon)$ de compósitos PU/sisal e de compósitos híbridos PU/sisal-bentonita. (a) $\sigma$ (MPa); (b) E (MPa); (c) $\varepsilon(\%)$ vestigados (Figura 4 a-c). Este comportamento foi atribuído à degradação oxidativa dos componentes individuais dos compósitos e dos híbridos. É sabido que tanto o poliuretano quanto às fibras de sisal degradam por exposição ao calor ${ }^{[16]}$. Os resultados indicam que os tempos e as temperaturas empregadas aqui, isto é, $110 \pm 5^{\circ} \mathrm{C}$ por até 32 dias promoveram a degradação dos compósitos investigados.

As Figuras também ilustram que, nos primeiros 3 a 4 dias de exposição térmica, houve um pequeno aumento na resistência $\mathrm{e}$ no módulo elástico de todos os compósitos (10\% em média) seguido de uma redução nas propriedades citadas após 4 dias de exposição térmica e que continuava até o tempo máximo (32 dias) de envelhecimento térmico utilizado neste estudo.

O aumento inicial na resistência e módulo elástico dos compósitos expostos termicamente é atribuído a reações de pós-cura da matriz termofixa ${ }^{[16]}$. Comportamento um pouco distinto foi apresentado para os compósitos híbridos com carga tratada com o sal Cetremide onde aumentos médios de aproximadamente $30 \%$ (ao invés dos $10 \%$ anteriormente citados) na resistência à tração e módulo elástico, nos primeiros dias de exposição térmica foram observados. Neste caso, atribui-se este comportamento à estabilidade térmica deste sa[ ${ }^{[17]}$.

$\mathrm{O}$ decréscimo na resistência à tração e no alongamento na ruptura dos compósitos híbridos (PU/sisal-bentonita 1:0,25:0,05) foi similar (50 e 15\% respectivamente) ao dos compósitos reforçados unicamente com sisal (PU/sisal 1:0,25). A incorporação da carga mineral ao compósito PU/ sisal, no entanto, provocou um decréscimo mais acentuado no módulo dos compósitos após 32 dias de exposição térmica visto que, em valores aproximados, a redução observada para o compósito PU/sisal foi de $20 \%$ e para o híbrido PU/ sisal-bentonita foi de $40 \%$.

A degradação térmica dos híbridos de carga mineral tratada com $\mathrm{HCl}$ foi mais intensa do que aqueles em que a argila foi organofilizada. A modificação ácida da bentonita além de destruir a estrutura da argila, levando inclusive à sua exfoliação, acaba por introduzir átomos de cloro na sua estrutura $^{[18]}$. Acredita-se que, quando os compósitos foram expostos termicamente, átomos de cloro tenham sido liberados, catalisando a degradação.

A redução na resistência e no alongamento na ruptura provocados por 32 dias de exposição térmica dos compósitos híbridos com bentonita organofilizada foi semelhante. Se comparadas à do híbrido com argila natural, a redução observada nestas propriedades foi inferior $(20 \%$ e $10 \%$ se comparados a 50 e $15 \%$, em média, respectivamente). Dentre os compósitos híbridos contento argilas quimicamente modificadas, o mais estável termicamente foi o híbrido poliuretano/sisal-bentonita modificada com o sal Cetremide. Acredita-se que este comportamento possa ser atribuído à maior estabilidade térmica apresentada pelo sal Cetremide se comparado ao sal Dodigen ${ }^{[17]}$.

\section{Conclusões}

Neste trabalho investigou-se o efeito da incorporação, do teor e da modificação química de uma carga mineral 
nanoparticulada nas propriedades mecânicas e no envelhecimento térmico dos compósitos PU/sisal. Os dados indicam que a inclusão da carga mineral sem tratamento (Bentonita sódica Brasgel PA) promoveu aumento as propriedades mecânicas dos compósitos. Valores otimizados para as propriedades mecânicas em tração e impacto foram obtidos com a incorporação de $5 \%$ em peso de carga. Modificações químicas na carga mineral promoveram aumentos subsequentes nas propriedades mecânicas dos compósitos. A modificação química mais eficaz no aumento das propriedades mecânicas do sistema investigado (PU/sisal-bentonita) foi o tratamento com ácido clorídrico $0,6 \mathrm{~N}$. Os resultados indicam que este tratamento provoca exfoliação da argila e reduz o tamanho dos aglomerados de carga. A exposição térmica, em estufa de circulação forçada de ar operando a $110{ }^{\circ} \mathrm{C}$ por até 32 dias, alterou as propriedades mecânicas em tração $(\sigma, \mathrm{E}, \varepsilon)$ dos compósitos. Em tempos curtos (até 4 dias) foram observados aumentos na resistência e módulo elásticos, que foram atribuídos a reações de pós-cura. Em tempos longos de exposição (32 dias) as propriedades mecânicas de todos os híbridos decresceram. No entanto, a resistência à tração e o módulo de elasticidade dos compósitos permaneceram superiores e o alongamento na ruptura inferior ao da matriz (PU) mesmo depois de envelhecidos termicamente. A organofilização da carga mineral com o sal Cetremide resultou em um compósito híbrido mais estável termicamente que os outros investigados neste estudo. Este comportamento foi associado à maior estabilidade térmica do sal Cetremide se comparado ao Dodigen. Dados de difração de raios-X indicaram que as reações de organofilização foram bem sucedidas e que houve formação de nanocompósitos poliuretano/sisal-bentonita quando a argila foi organofilizada. Dados de MEV evidenciaram a presença de aglomerados quando a argila foi tratada com esses sais, indicando a formação de uma estrutura composta de nanocompósito intercalado e de microcompósito.

\section{Agradecimentos}

Os autores agradecem à Proquinor S.A. e a Bentonit União Nordeste (BUN) pelos insumos; à RENAMI pelo suporte financeiro; ao grupo de cerâmica de DEMa/UFCG pelo tratamento das argilas e ao CNPq pelo apoio financeiro ao projeto PADCTIII/CNPq \# 620343/98-2 e pela bolsa PQ concedida a Carvalho.

\section{Referências Bibliográficas}

1. Carvalho, L. H. - "Chemical Modification of Fibers for Plastics Reinforcement in Composites". In: Lignocellulosic - Plastics Composites, p. 197, São Paulo-SP (1997).

2. Joseph, K.; Thomas, S. \& Pavithran, C. - Composites Science and Technology, 53, p. 99 (1995).
3. Schuh, T. \& Gayer, U. - "Automotive Applications of Natural Fiber Composites". In: Lignocellulosic Plastics Composites, p. 181, São Paulo - SP (1997).

4. Joseph, K.; Thomas, S.; Pavithran, C. \& Brahmakumar, M. - Journal of Applied Polymer and Science, 47, p. 1731 (1993).

5. Saujanya, C. \& Radhakrishnan, S. Polymer, 42, p. 6723 (2001).

6. Yao, K. J.; Song, M.; Hourston, D. J. \& Luo, D. Z. Polymer, 43, p. 1017 (2002).

7. Kawasumi, M.; Hasegawa, N.; Kato, M.; Usuki, A. \& Okada, A. Macromolecules, 30, p. 6333 (1997).

8. Akkapeddi, M.K. - Polymer Composites, 21, p. 576 (2000).

9. Valenzuela Díaz, F. R.- Anais do $43^{\circ}$ Congresso Brasileiro de Cerâmica, Florianópolis, p. 43201-43213, 1999. 1 CD-Rom.

10. Bledzki, A. K. \& Gassan, J. - Polymer Science, v. 24, p. 221-274 (1999).

11. Callister Jr., W.D. - Fundamentals of Materials Science and Engineering - An integrated approach, 2 Ed., John Wiley \& Sons (2005).

12. Correa, C.A, Fonseca, C.N.P., Neves, S., Razzino, C.A, Hage Jr., E. - Polímeros: Ciência e Tecnologia, v.13, nÚ3, 154 (2003).

13. Fonseca, V.M., Fernandes Jr., V.J., Carvalho, L.H., d'Almeida, J.R.M. - Journal of Applied Polymer Science, v.94, 1209-1217 (2004).

13. Hull, D. \& Clyne, T. W. - An Introduction to Composites Materials. 2 Ed. Cambridge University Press (1996).

14. Pinto, M.R.|O. - "Desenvolvimento de compósitos poliméricos a base de poliuretano derivado do óleo de mamona, sisal e bentonita" - Tese de Doutorado, Universidade Federal de Campina Grande (2004).

15. Morais, S. A. - "Argila Esmectítica Como Carga Para o Polipropileno. Efeito de Modificações Ácidas na Carga”. Dissertação de Mestrado, Universidade Federal da Paraíba, Brasil (1995).

16. Alsina, O.L.S., Carvalho, L.H., Ramos Filho, F., d'Almeida, J.R.M. - Polymer Testing, v. 24, p.81 (2005).

17. Silva, S.M.L. ; Ramos Filho, F.G.; Melo, T.J.A.; Rabello, M.S. - Polymer Degradation and Stability, v. 89, p. 383 (2005).

18. Souza Santos, P. - Ciência e Tencologia de Argilas, Vol. 1, 2a Ed, Editora Edgar Blucher (1989).

Enviado: 04/03/05

Reenviado: 05/08/05

Aprovado: 11/08/05 